\section{P0-0206 THE EFFECTIVENESS OF VARIOUS TREATMENT REGIMENS IN HOSPITALISED CHILDREN WITH BRONCHIOLITIS}

${ }^{1} \mathrm{E}$ Shmueli, ${ }^{2} \mathrm{~T}$ Berger, ${ }^{3} Y$ Herman, ${ }^{1} \mathrm{E}$ Rom, ${ }^{1} \mathrm{E}$ Bilavsky, ${ }^{1} \mathrm{~L}$ Ashkenazi-Hoffnung, ${ }^{2} \mathrm{BZ}$ Garty, ${ }^{3}$ S Ashkenazi, 'J Amir. 'Department of Pediatrics C, Schneider Children's Medical Center, Petach Tikvah, Israel; ${ }^{2}$ Department of Pediatrics B, Schneider Children's Medical Center, Petach Tikvah, Israel; ${ }^{3}$ Department of Pediatrics A, Schneider Children's Medical Center, Petach Tikvah, Israel

\subsection{6/archdischild-2014-307384.861}

Aim To evaluate the effectiveness of various treatment regimens for bronchiolitis in hospitalised children in three general paediatric wards in which different treatment protocols are customary. Patients and methods Data was retrospectively collected for all hospitalised children under two years of age with clinical bronchiolitis, between October 2012 and March 2013.

Results During the study, a total of two hundred eighty six children were hospitalised with bronchiolitis in wards A, B and C. Clinical and laboratory parameters upon admission were similar among the patients in the three wards. The treatment differed between the wards, as in ward C, use of antibiotics and hypertonic saline inhalations was significantly less $(\mathrm{p}<0.001)$. Admission course and outcome were also significantly different among the wards: mean number of days with measured saturation $<92 \%$ and mean length of hospital stay were lower in ward C compared to wards A and B (1.8 days vs. 2.8 and 2.9 days, $\mathrm{p}=0.001$ and 3.9 days vs. 5.0 and $4.4, \mathrm{p}=0.012$, respectively).

Multivariate analysis showed that low saturation upon admission, higher WBC count and the use of hypertonic saline inhalations were predictive of a longer period of saturation $<92 \%$ and a longer hospital stay. Similar results were found in the subgroup of two hundred and three children with positive respiratory-syncytial-virus nasal wash.

Conclusions No proof was found as to the added effectiveness of different treatments in bronchiolitis. Furthermore, the use of hypertonic saline inhalations might be associated with a longer period of low saturation and a longer hospital stay.

\section{PO-0207 EPIDEMIOLOGY OF STENOSING LARYNGOTRACHEITIS (CROUP) IN CHILDREN IN THE CITY OF VINNYTSYA, UKRAINE}

L Stanislavchuk. Pediatric Infection Disease, Vinnytsya National Medical University n.a. M. Pyrogov, Vinnytsya, Ukraine

\subsection{6/archdischild-2014-307384.862}

Introduction Croup is one of the most common respiratory illnesses presenting to the emergency department (ED) in early childhood. The epidemiology of this disease was analysed.

Methods During the 14 years period from 1995 to 2008 a total number of 4914 children aged 0-14 years, who made crouprelated visits to EDs in the city of Vinnytsya, Ukraine, were identified to obtain all encounters for croup made by children.

Results During the study period, the annual incidence of croup had varied from 45.7 to 96.6 cases per 10000 child population (Figure). Since 2005, annual incidence rates had increased. Most children $(85.7 \%)$ were younger than 6 years of age; the peak incidence occurred during the second year of life (24.4\%); the male to female ratio was $2.2: 1.69 .1 \%$ of children had 1 croup episode, $21.5 \%$ - 2-3 croup episodes, $9.4 \%$ - 4 or more croup episodes.

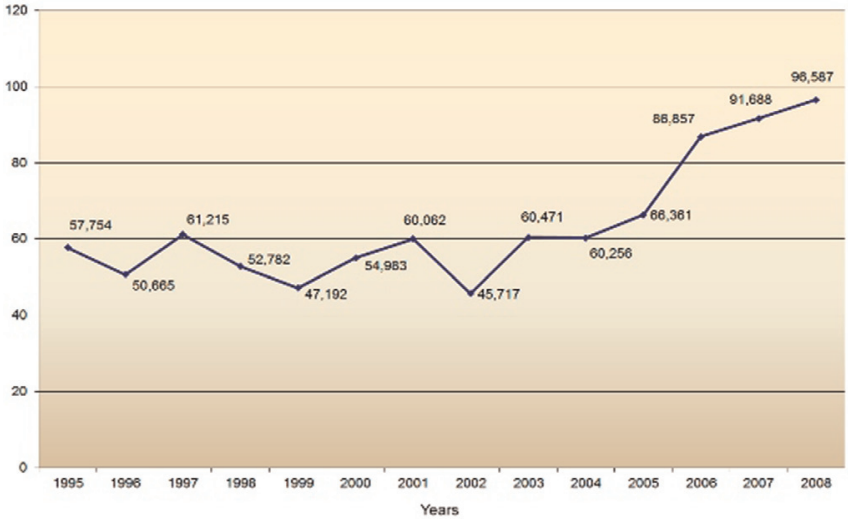

Abstract P0-0207 Figure 1 The annual incidence of croup in the city of Vinnytsya, Ukraine, 1995-2008; (cases per 10000 child population).

Conclusions Croup is one of the respiratory illnesses in early childhood. The boys are more commonly affected than girls. The risk of croup recurrence is high.

\section{PO-0208 SISONAL AND DAILY PATTERNS OF CROUP BETWEEN 1995 AND 2008 IN VINNYTSYA, UKRAINE}

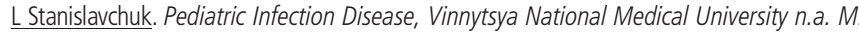
Pyrogov, Vinnytsya, Ukraine

\subsection{6/archdischild-2014-307384.863}

Introduction Seasonal variation in croup has been well documented by at least 12 reports, bat there are some regional differences. Evidence is lacking, however, for daily variation in croup. Aims To determine seasonal and daily variation in croup.

Methods We reviewed all emergency department calls for croup in Vinnytsya region (Ukraine) over fourteen years (1995-2008).

Results The number of emergency department calls per month (Figure 1) was significantly higher in spring and autumn months and lower in summer for croup. Mean monthly calls for croup ranged from $46 \%$ below average in August to $49 \%$ above average in October. The number of emergency calls for crop per hour was significantly higher from 1 to 4 AM (Figure 2). During this time there were $31 \%$ of daily calls. The lowest rate of calls was during the daytime, which rapidly increased from 11 PM. Conclusion We confirmed seasonal variation for croup and revealed specific daily pattern for croup based on fourteen years observation in Vinnytsya region of Ukraine.

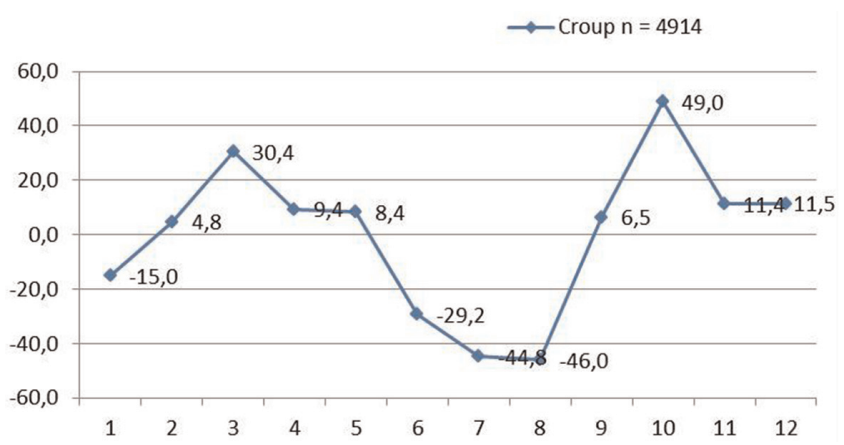

Abstract P0-0208 Figure 1 Monthly percentage variation in emergency department call for croup in Vinnytsya, Ukraine, 1995-2008; (0 represents the sum monthly variations) 